\title{
In-situ multi-analytical characterization of original and decay materials from unique wall mirrors in the House of Gilded Cupids, Pompeii
}

\author{
Marco Veneranda' , Silvia Fdez-Ortiz de Vallejuelo ${ }^{1}$, Nagore Prieto-Taboada ${ }^{1}$, Maite Maguregui ${ }^{2}$, \\ Iker Marcaida ${ }^{1}$, Héctor Morillas ${ }^{1}$, Alberta Martellone ${ }^{3}$, Bruno de Nigris $^{3}$, Massimo Osanna ${ }^{3}$, Kepa Castro ${ }^{1}$ \\ and Juan Manuel Madariaga ${ }^{1,4^{*}}$ (D)
}

\begin{abstract}
The House of Gilded Cupids (Regio VI, Insula 16,7,38) was unquestionably one of the most important residences of Ancient Pompeii, where important archaeological artefacts such as mural paintings, mosaics, sculptures and lalariums were rediscovered. This work characterizes two wall mirrors that, together with those recovered from the House of Efebo and the Domus of Euplia, represent the only ones found in the archaeological site of Pompeii. The 2015 and 2016 expeditions of the Analytica Pompeiana Universitatis Vasconicae project performed an in situ multi-analytical study, using only portable non-destructive analytical techniques. Molecular data provided by Raman spectroscopy suggested obsidian was the reflective matrix for both mirrors. Elemental data provided by energy dispersive X-ray fluorescence and laser induced breakdown spectroscopy (LIBS) systems were concordant with Raman spectroscopic results, enabling the detection of $\mathrm{Ca}, \mathrm{K}, \mathrm{Al}$ and $\mathrm{Na}$ as the main elements included in the Si matrix characteristic of obsidian igneous rocks. The LIBS data confirmed the presence of obsidian hydration layers. All techniques were used to investigate the degraded white and yellow crusts of the mirrors. Gypsum $\left(\mathrm{CaSO}_{4} \cdot 2 \mathrm{H}_{2} \mathrm{O}\right)$ and nitrocalcite $\left(\mathrm{Ca}\left(\mathrm{NO}_{3}\right)_{2} \cdot 4 \mathrm{H}_{2} \mathrm{O}\right)$ were identified in the white areas and gypsum and goethite $(\mathrm{a}-\mathrm{FeOOH})$ in the yellow crusts. LIBS depth profiling on the white crusts found a layer of nitrocalcite on top of the gypsum layer. Gypsum and goethite were proposed to form after partial dissolution of the mortars patches (with high iron contents) used in modern restorations around the mirrors, followed by a reprecipitation on the surface of the mirrors. Nitrocalcite was proposed to form after the attack of atmospheric $\mathrm{NO}_{x}$ on gypsum crusts. These results represent the first analytical work focused on the study of these unique mirrors and provide the knowledge needed for defining more adequate conservation treatments.
\end{abstract}

\section{Introduction}

The ancient city of Pompeii (Naples, Italy), along with Herculaneum, Oplontis, Stabiae and many other Roman settlements, was destroyed for the eruption of the Mount Vesuvius in 79 AD [1]. Volcanic ashes, pumices and debris that poured down during the volcanic eruption sealed those cities, favoring their optimal preservation during centuries. Excavation of the

\footnotetext{
*Correspondence: juanmanuel.madariaga@ehu.eus

${ }^{1}$ Department of Analytical Chemistry, University of the Basque Country (UPV/EHU), PO Box 644, 48080 Bilbao, Spain

Full list of author information is available at the end of the article
}

archaeological site of Pompeii in 1728 gave birth to a renewed interest towards the study of the Ancient Roman civilization [2], becoming a fundamental stop of the Grand Tour (traditional trip undertaken by European intellectuals in search of the roots of Western civilization art and culture) [3]. The historical, artistic and cultural value of this Roman city was universally acknowledged in 1997, when it was endorsed to the World Heritage List of the United Nations Educational, Scientific and Cultural Organization (UNESCO) [4]. Since then, the turnout of tourists has been steadily increasing and currently averages 3.2 million visitors 
a year. Pompeii is the most visited cultural site of Italy after the Colosseum of Rome [5].

Even though the excavation of Pompeii offered a full and unique picture of the daily life of ancient Roman civilization, the removal of volcanic materials triggered the activation of several deterioration processes [6]. Thermal and humidity fluctuations, exposure to sunlight, atmospheric pollution and biological colonization, are just a few of the many factors causing the irremediable loss of unique and priceless artworks [7-9].

Considering the extreme complexity of variables influencing the conservation of these ancient remains, the work of conservators is supported by experts from other fields, including chemists, physicists, archaeologists and geologists. In this sense, the preservation of Pompeii (and of Cultural Heritage in general) clearly turns into a transdisciplinary commitment in which scientific disciplines have a steadily increasing importance [10].

In this context, the IBeA research group from the University of the Basque Country (UPV/EHU) [11] collaborated with the Archaeological Park of Pompeii, within the Analitica Pompeiana Universitatis Vasconicae (APUV) project [12] by performing research aimed at deepening the understanding of Pompeian remains and providing important guidelines to plan future conservation works. In the past decade, the APUV project has focused efforts for the scientific analysis of artworks preserved in some of the most important residences of the city, such as the House of Marcus Lucretius (IX 3,5/24) [6, 13-16], the House of Ariadne (VII 4,31/51) [17, 18] and the House of the Gilded Cupids (VI. 16.7, 38) [19].

Among them, the latter stood out by the extraordinary richness and variety of archaeological remains found therein. The House of the Gilded Cupids takes its name from golden plates decorated with cupids figures, which adorned one of the main rooms of the residence. Graffiti indicates the owner in Cn. Poppaeus Habitus, related to Poppea Sabina, Nero's second wife [20]. According to literature, the residence was built in the third century $\mathrm{BC}$, resettled in the first century $\mathrm{BC}$ and at the time of the Vesuvius eruption (A.D. 79), consisted of a large peristyle surrounded by more than 15 rooms decorated with frescoes of the I, III and IV style.

The house was reclaimed from volcanic debris thanks to the archaeological excavations started in the twentieth century AD. In addition to the frescoes mentioned above, the work of archaeologists led to the recovery of further remains of inestimable value, including a fountain, polychrome mosaics, marble sculptures and Roman and Egyptians lalariums [21]. The discovery of two mirrors attached to the east wall of the peristyle, together with those recovered from the House of Efebo (I 7,10-12.19) and the Domus of Euplia (I 9, 5-7), are important as they are representative of the unique wall mirrors found in this archaeological site [20].

In spite of the rarity of these finds, the hypotheses proposed regarding their composition and their origin have never been supported by analytical studies [22]. It is important to note that these mirrors have undergone restoration work, which is undocumented, and despite this previous intervention these items clearly require further conservation. The presence of two different kinds of crusts is clearly compromising the reflective property of the mirrors.

The IBeA group has undertaken an analytical investigation using portable instruments avoid destructive sampling [23]. Elemental and molecular techniques were employed in a complementary manner to (1) study the chemical composition of the mirror matrix, (2) identify the composition of the degradation threatening their conservation and (3) propose hypotheses to explain the observed decay mechanisms. This work further highlights the indispensable role played by scientific research in understanding, safeguarding and enhancing Cultural Heritage assets.

\section{Experimental \\ Raman spectroscopy}

The molecular characterization of decay materials was accomplished by means of the InnoRamTM-785S Raman spectrometer. This system is equipped with a $785 \mathrm{~nm}$ red laser (maximum power of $300 \mathrm{~mW}$ ) and operates in a range between 175 and $3200 \mathrm{~cm}^{-1}$ with a mean spectral resolution of $4.5 \mathrm{~cm}^{-1}$.

Approximately 50 measurements were collected using the hand-held microprobe (spotsize approximately $150 \mu \mathrm{m}$ ) with measurement times varying from 2 to $30 \mathrm{~s}$, over a spectral range from 200 to $3000 \mathrm{~cm}^{-1}$ and accumulation number varying from 5 to 20 (depending on the region of interest, the presence of fluorescence and the signal-to-noise ratio). The laser power was reduced to $30 \mathrm{~mW}$ in order to avoid any thermal photodecomposition of the materials under analysis. Raman spectra were acquired using BWSpec ${ }^{\mathrm{TM}} 3.26$ (B\&WTEK Inc., USA) software, and processed by Nicolet Omnic 7.2 software (Madison, USA). Spectral interpretation was based on the comparison of the recorded spectra with those of spectral libraries $[24,25]$.

\section{Hand held energy dispersive X-ray fluorescence (HH-ED-XRF)}

Energy dispersive X-ray fluorescence data were collected using a XMET5100 spectrometer (Oxford Instruments, Oxford UK) equipped with a rhodium anode X-ray tube (operating at $45 \mathrm{kV}$ ). The analyzer has a silicon drift 
detector that provides an energy resolution of $150 \mathrm{eV}$ (calculated for the $\mathrm{Mn} \mathrm{K \alpha}$ line) and a spectral resolution of $20 \mathrm{eV}$. The analyses were performed directly by placing the sampling interface on the mirror surface. Data acquisition was carried out using a personal digital assistant (PDA) integrated into the instrument. To improve the limit of detection, measurements were acquired for $100 \mathrm{~s}$ (real time). Considering that ED-XRF is a non-destructive technique, it was selected to carry out the over elemental screening of the mirrors ( 25 and 10 point of analysis were selected from Mirror 1 and 2 respectively).

\section{Laser induced breackdown spectroscopy (LIBS)}

Additional elemental studies were performed using the EasyLIBS IVEA (model Easy 2C) LIBS system. This instrument employs a pulsed Nd:YAG laser, with the possibility of operating in a dual pulse mode, emitting at a wavelength of $1064 \mathrm{~nm}$. The laser energy per pulse on the sample is higher than $25 \mathrm{~mJ}$ with a repetition rate of $1 \mathrm{~Hz}$ and the duration of laser pulse is $4-5 \mathrm{~ns}$. Measurements were performed with the double pulse mode. An optimized delay time of $50 \mu$ s to the laser pulse and a gate width of $5 \mathrm{~ms}$ were employed. All spectra were accumulated over 1-3 laser-shots. The Easy $2 \mathrm{C}$ model consists of an optic probe that allows focusing the laser connected to a computer and to three spectrometers, covering the ultraviolet (UV, 196-419 nm), of the visible (VIS, 420$579 \mathrm{~nm}$ ) and near infrared (NIR, 580-1000 nm) spectral ranges respectively. The software used for automatic acquisition, control, visualization and processing of the spectra was the AnaLIBS version 6.3. The analyses were performed directly placing the sampling interface on the mirrors. Taking into account the signal-to-noise ratio (SNR) of the collected LIBS spectra only peaks whose intensity was greater than a threshold of $0.5 \sigma$ of the total spectrum (under 150-200 counts) were considered for line determination. Data interpretation was carried out using the NIST database [26]. Considering that LIBS is a micro-destructive technique, its use was limited to the study of the most interesting spots of interest (12 in total including both, superficial and in-depth analysis).

\section{Results}

\section{Mirrors composition}

The mirrors located on the west wall of the peristyle are two of the most interesting archaeological items recovered from the House of the Gilded Cupids. According to literature, during the Roman Empire mirrors were manufactured either by floating a molten metal alloy (commonly formed of lead, antimony and tin) onto a thin layer of handcrafted transparent glass, or by applying a smooth surface of vitreous materials of volcanic origin (e.g., obsidian) [27]. Molecular and elemental analysis were performed to identify the composition of these artefacts by means of portable Raman, ED-XRF and LIBS systems (the region of interest are marked on images in Fig. 1).

In-situ molecular analysis was carried out by collecting Raman spectra from several non-degraded regions of the mirrors. As can be seen in Fig. 2, the spectra collected from the two artefacts are concordant and show an intense broad band centred at $1347 \mathrm{~cm}^{-1}$ together with three weak vibrational signals at 589, 795 and $1097 \mathrm{~cm}^{-1}$.

According to literature, the broad band centred at $1350 \mathrm{~cm}^{-1}$ is a typical luminescence effect provided by glassy compounds when excited with a laser emitting at $785 \mathrm{~nm}[28,29]$, while the weak band at $589 \mathrm{~cm}^{-1}$ is produced by the stretching-bending vibration across the $\mathrm{Si}-\mathrm{O}-\mathrm{Si}$ bridging oxygen of silicate glasses [30]. However, the Raman signals detected at 795 and $1097 \mathrm{~cm}^{-1}$ were fundamental for establishing the possible source of the glass material. Indeed, the published works dealing with the characterization of volcanic glasses proved that Raman spectra containing a band around $800 \mathrm{~cm}^{-1}$ and a massif between 950 and $1150 \mathrm{~cm}^{-1}$ are characteristic features of obsidians [31]. In this work, the stretching vibrations of isolated $\mathrm{SiO}_{4}{ }^{2-}$ tetrahedral are assigned to the band at $795 \mathrm{~cm}^{-1}$ while the broad signal centred at $1097 \mathrm{~cm}^{-1}$ has the contribution of three bands related with vibrations of silica groups containing 0,1 and 2 nonbridging oxygens.

In order to confirm the Raman data interpretation, the same regions of interest were studied using both LIBS and ED-XRF systems.

ED-XRF analysis were performed to obtain a representative matrix measurement, as the X-ray beam spot size was $9 \mathrm{~mm}$. Complementary information was collected from light elements (e.g., $\mathrm{Al}, \mathrm{Mg}, \mathrm{Na}$ ) from LIBS, which provided information about the composition of vitreous materials to enable their identification.

As can be seen in Fig. 3, LIBS analysis from the nondegraded areas identified 15 different elements $(\mathrm{H}, \mathrm{Li}, \mathrm{C}$, $\mathrm{O}, \mathrm{Na}, \mathrm{Mg}, \mathrm{Al}, \mathrm{Si}, \mathrm{K}, \mathrm{Ca}, \mathrm{Ti}, \mathrm{Cr}, \mathrm{Fe}, \mathrm{Sr}$ and $\mathrm{Ba}$ ). Among them, Si (main peak at $251.6 \mathrm{~nm}$ ), $\mathrm{Na}$ (main peak at $588.9 \mathrm{~nm}$ ), $\mathrm{Al}$ (characteristic peaks at 309.3, 394.4 and $396.2 \mathrm{~nm}$ ) Ca (main peaks at 393.6 and $396.9 \mathrm{~nm}$ ), $\mathrm{Mg}$ (main peak at $281.0 \mathrm{~nm}$ ) and $\mathrm{K}$ (main peaks at 766.5 and $770.4 \mathrm{~nm}$ ) were detected as major elements of both mirrors.

Taking the presence of Si as granted in both man-made and natural volcanic glasses, the presence of significant amounts of calcium, potassium, aluminium and sodium provide additional evidence to support Raman spectroscopic results, that obsidian igneous rock was used as the mirror matrix. These are the main elements of obsidian glass [32, 33] and are responsible for their characteristic 


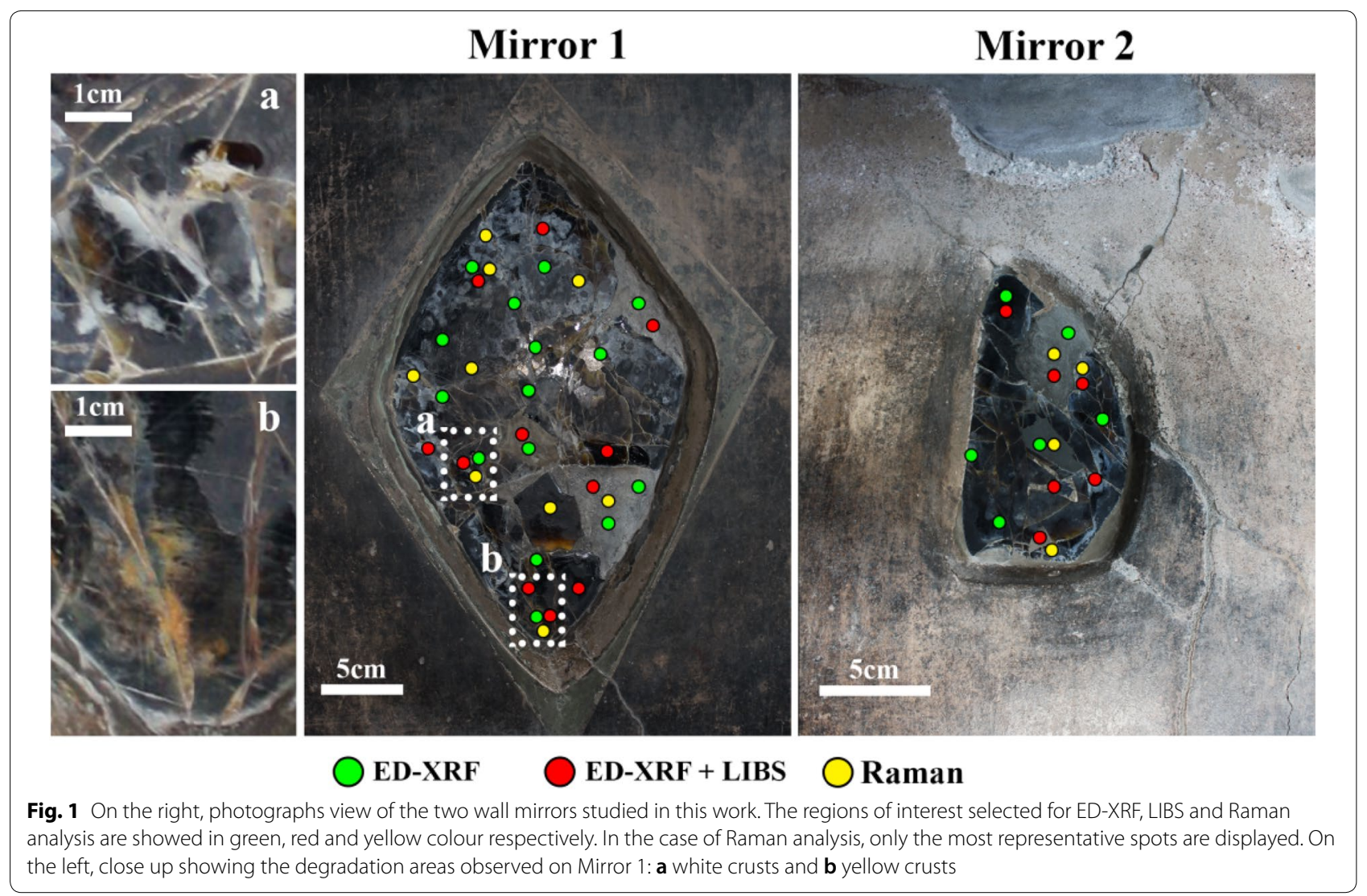

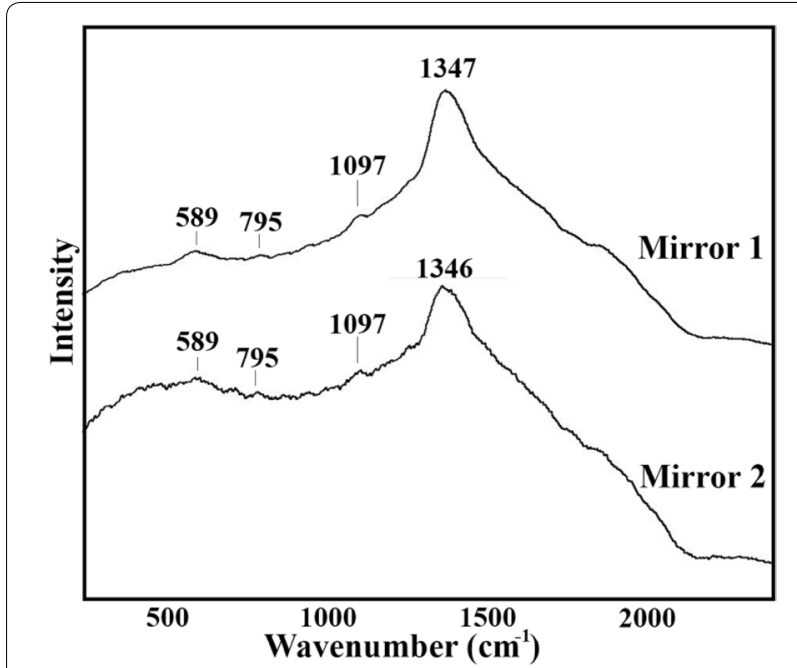

Fig. 2 Raman spectra collected from the black matrix of Mirrors 1 and 2 using the portable innoRam ${ }^{\mathrm{TM}} 785 \mathrm{~S}$ spectrometer

brown-black colour. The elemental composition of obsidians is the result of specific geological processes and can be chemically classified as peralkaline, subalkaline, metaluminous and peraluminous, according to their aluminium, calcium, sodium and potassium oxides content, respectively [32].

Among the many elements detected by LIBS was the presence of an intense hydrogen emission line $(656.3 \mathrm{~nm})$, the LIBS system used in this work does not work under vacuum conditions. Therefore the origin of this hydrogen signal could be due to the contribution of any compound containing water or hydroxyls in the analysed region or due to atmospheric humidity as there is an open path between the detector and the sample under analysis. The presence of $\mathrm{H}$ on the obsidian surface could be attributed to hydration. Obsidian is a metastable igneous rock containing a low percentage of water (below 1.5 wt\%) [34]. After cooling and solidification, obsidian can absorb water, forming hydrated glasses phases such as pitchstone $\left(\mathrm{H}_{2} \mathrm{O}\right.$ content around 7\%) [35] and above all perlite $\left(\mathrm{H}_{2} \mathrm{O}\right.$ content up to 2-6\%) [36].

To establish if the surfaces of the two mirrors were hydrated, several LIBS were collected on the area free of any degradation product. LIBS is a micro-destructive technique as each laser shot generates a crater with an approximate diameter of $200 \mu \mathrm{m}$ and a depth of about $5 \mu \mathrm{m}$ (the size of the crater may vary according to the characteristics of the material under analysis). The hydration of the obsidian surface can reach a 


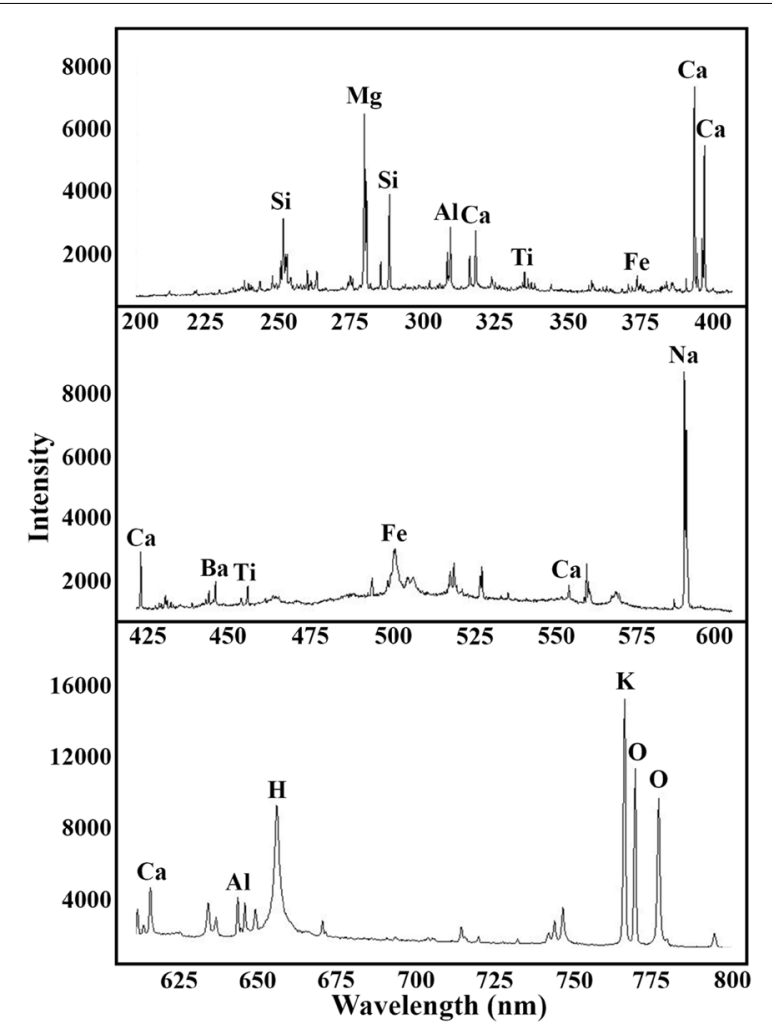

Fig. 3 LIBS spectra collected from the silicate-based matrix of Mirror 1. The major presence of $\mathrm{Si}, \mathrm{Mg}, \mathrm{Al}, \mathrm{Ca}, \mathrm{Na}$ and $\mathrm{K}$ as major elements can be clearly observed

depth of $10-20 \mu \mathrm{m}$ depending on the age of the obsidian [36]. Thus, successive laser shots in the same area could remove all of the hydrated layer reaching the inner part of the matrix where water is not present. If the intensity of the signal is plotted as a function of the number of shots, the initial shots would have hydrogen from the hydrated obsidian and the atmospheric water while the shots (after removing the hydrated layer) will have only the contribution from the atmospheric water.

Figure 4 illustrates this trend where numerous measurements from the same spot were collected from a non-degraded obsidian surface. The highest hydrogen signals are collected on the initial pulse, decreasing until a steady state is reached after the first 8-10 measurements, indicating that the hydration layer has been completely ablated. The only hydrogen signal remaining water when the inner part of the obsidian is analysed can be attributed to the atmosphere.

Obsidian hydration is a very slow but inexorable natural process. The measurement of the hydrated layer thickness has been used since 1960 as a geochemical method for determining the age of obsidian archaeological artefacts [37-39]. Friedman et al. [36] determined that the hydration rates of obsidian depend primarily on temperature. In their study, the hydration rate of obsidian samples exposed to different climatic conditions was measured and compared. Their results proved that the thickness of a hydration layer on obsidian samples exposed to temperate climates (that is, the temperature conditions that can be found in Pompeii) grew at a rate of $4.5-6.5 \mu \mathrm{m}$ every 1000 years. Considering that Pompeian artefacts are at least 2000 years old, the superficial hydration layer thickness of obsidian mirrors is likely to be approximately $10-20 \mu \mathrm{m}$. In addition to explaining the origin of the detected hydrogen, it provides further evidence of the use of obsidian for the manufacture of the two mirrors.

Although volcanic materials from Vesuvius were frequently used in Pompeii (e.g., as aggregate in mortars to improve their mechanical properties [17]), previous studies prove that obsidian can be only formed by the rapid cooling of rhyolitic lava streams, whose typical $\mathrm{SiO}_{2}$ concentration exceeds $70 \mathrm{wt} \%$ [40]. In 2008, Cioni et al. [41] presented an interesting study in which the physical and compositional parameters of Vesuvius volcanic materials from recent and ancient times (up to 10,000 years ago) were investigated. The authors reported that Vesuvius lava contains between 47 and 67 $\mathrm{wt} \% \mathrm{SiO}_{2}$, which is below the limit for obsidian formation whereby the $\mathrm{SiO}_{2}$ concentration typically exceeds $70 \mathrm{wt} \%$ [40]. Although volcanic materials from Vesuvius were frequently used in Pompeii it can be assumed that the analysed mirrors were not made of local materials. This finding opens up new interesting questions regarding the obsidian provenance.

Comparative analytical studies can provide important insight regarding the provenance of ancient materials and artifacts [42, 43]. For example, a review summarized the petrographic and geochemical features of several Roman volcanic millstones [44]. This study identified the four main volcanic rock source areas exploited by the Romans to manufacture millstones and contributed to better defining trade networks and cultural links in different periods of the Roman Empire.

A similar approach could be used to locate the geological origin of the raw material used to produce the Pompeian mirrors.

The work of Cann and Renfrew [45] indicates that, in the broad geographic area that includes Europe, West Asia and Africa, only 21 main sources of obsidian can be found. A thorough study of Pompeian mirrors could be used to provide the obsidian provenance.

Bellot-Gurlet et al. [31], successfully used Raman spectroscopy to identify spectral differences among samples collected from the four most important obsidian sources 

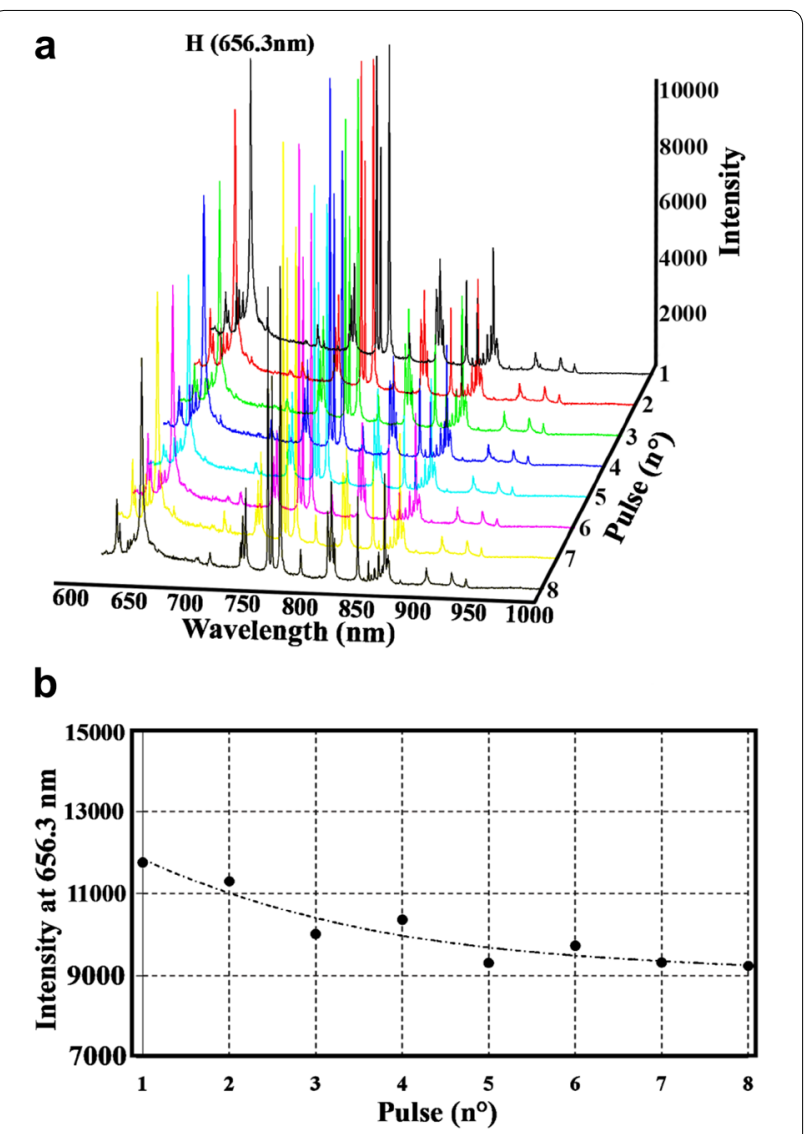

Fig. 4 a LIBS spectra in the NIR wavelength region (600-1000 nm) collected from the silicate-based matrix of Mirror 1, analysing several times on the same spot. $\mathbf{b}$ Graph showing how the intensity of the main hydrogen emission line decreases as a function of the number of laser shots

in the western Mediterranean (Lipari, Palmarola, Pantelleria and Sardinia). According to the presented results, reliable provenance studies could be carried out through the deconvolution of the vibrational band between 950 and $1150 \mathrm{~cm}^{-1}$.

The intensity of the Raman bands in the spectra collected from the obsidian mirror matrix are reduced in comparison with those reported by Bellot-Gurlet et al. [31], which complicates determining the obsidian provenance. This is attributed to the different excitation lines used, with this study using $785 \mathrm{~nm}$ compared to $532 \mathrm{~nm}$ used to investigate the Mediterranean obsidian [31]. Carter et al. [46] demonstrated that the Raman profile collected from obsidian is dependent upon the wavelength of the excitation line, with the presence of rare earth elements contributing to a luminescence which is observed in addition to the Raman signal. Other works have been also proved that the vibrational profile of obsidian Raman spectra also depends on the degree of weathering of surface under analysis [47].
Despite the added complication of the different spectral intensities, it is important to highlight in the Raman spectra collected from both mirrors the presence of a band centred at $1097 \mathrm{~cm}^{-1}$ which fit with the vibrational band profile collected from Pantelleria (Italy) obsidian samples [31]. Thus, the Raman characterization of these two Pompeian mirrors could help on shed light on the provenance of raw materials.

\section{Degradation forms}

Extensive degradation was observed on both mirrors. As shown in Fig. 5, the images collected from Mirror 1 confirmed the presence of mineral grains and layers on the surface and in the cracks of the obsidian. Characterization to identify pathways and guide conservators through the planning of an optimal intervention was a necessity.

According to information provided by the Archaeological Park of Pompeii, during the past century the House of the Gilded Cupids has undergone to several conservation works, the most recent in 2012. Despite a lack of detailed documentation, the mirrors were clearly subjected to specific conservation treatments. The main evidence is provided by the mortar patches in the mirrors used to join the obsidian fragments. Two types of filling materials were observed based on their different colours, white and grey, respectively. This detail reinforces the hypothesis that these mirrors were subjected to at least two interventions.

Mirror 1 exhibits the most intense degradation problems, mainly consisting of white crusts damaging the black and shiny appearance of the volcanic glass. The structure and the shape of these white crusts suggested that are the result of two different degradation processes.

As can be seen in Fig. 1a, white incrustations overlapping the surface of Mirror 1 were detected in close proximity to the materials used to fill the obsidian gaps. In the lower part of the mirror, a yellow crust was also detected (Fig. 1b). LIBS and ED-XRF measurements were collected from the white crusts as well as from the conservation mortars. The elemental analysis of the degradation identified $\mathrm{Ca}$ and $\mathrm{S}$, the most abundant elements, suggesting the presence of sulphate-based compounds. In the XRF spectra of Fig. 6, the Fe concentration in the yellow crusts is higher than in the white ones, which indicates the additional presence of iron-based compounds.

Raman spectroscopy of these same crusts clearly identified the presence of gypsum $\left(\mathrm{CaSO}_{4} \cdot 2 \mathrm{H}_{2} \mathrm{O}\right.$ main Raman peaks at 414, 1008 and $\left.1134 \mathrm{~cm}^{-1}\right)$ in both white and grey mortars (Additional file 1: Table S1). The additional presence of nitrocalcite $\left(\mathrm{Ca}\left(\mathrm{NO}_{3}\right)_{2} \cdot 4 \mathrm{H}_{2} \mathrm{O}\right.$ main Raman peak at $1050 \mathrm{~cm}^{-1}$ ) in the white crusts was often detected together with calcium sulphate (see Fig. 7a). 


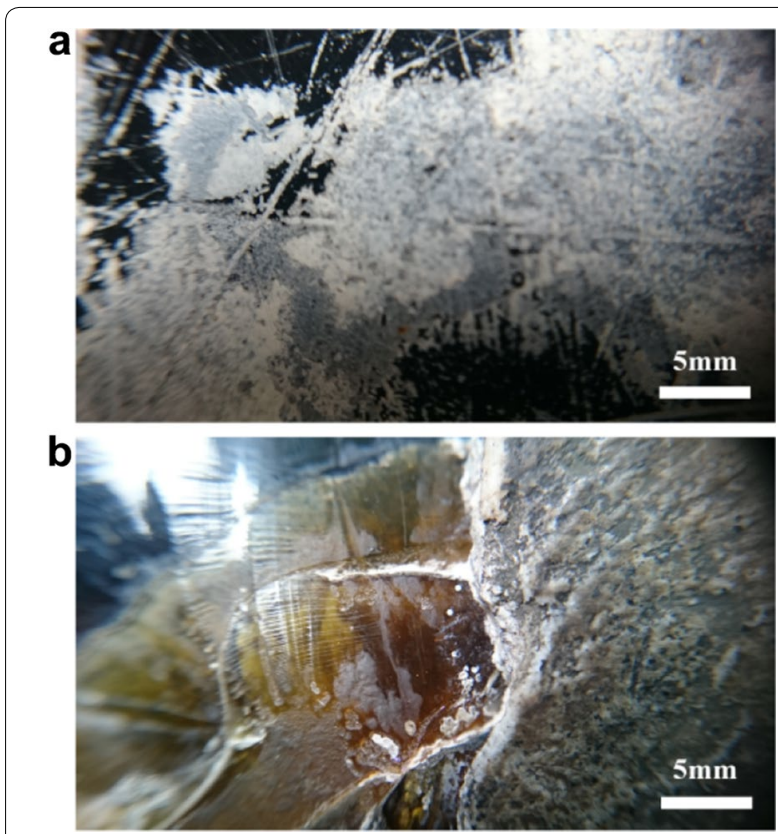

Fig. 5 Optical images of Mirror 1 showing degradation. The white crusts extend over the black surface of the obsidian (a) and along the cracks in the obsidian matrix (b)

Smaller white crusts were also found on the surface of Mirror 2 but in this case, the molecular analysis highlighted the presence of gypsum alone (see Fig. 8).

The identification of nitrocalcite was based on the position and the Full Wide at Half Maximum (FWHM) value of the Raman band at $1050 \mathrm{~cm}^{-1}$ (produced by the symmetric stretch of $\mathrm{NO}_{3}$ [48]). Niter $\left(\mathrm{KNO}_{3}\right)$ and nitrocalcite both have a Raman band in the same position, however they can be differentiated based on their FWHM values, FWHM $=8 \mathrm{~cm}^{-1}$ for $\mathrm{KNO}_{3}$ and $\mathrm{FWHM}=22 \mathrm{~cm}^{-1}$ for $\mathrm{Ca}\left(\mathrm{NO}_{3}\right)_{2} \cdot 4 \mathrm{H}_{2} \mathrm{O}$ respectively [49, 50]. In the case of the spectra represented in Fig. 7a, the mean FWHM value is approximately $20 \mathrm{~cm}^{-1}$ clearly indicating the presence of nitrocalcite, although the presence of niter cannot be ruled out because its Raman band could be overlapped by the nitrocalcite band (secondary bands could help to disclose this issue, but they are not visible in the collected spectra).

Taking into account that the filling product used during past conservation works contained gypsum, the development of white crusts in the close proximity to the mortars patches was probably due to a lixiviation/recrystallization process. Lixiviation processes generally occur in the presence of high humidity levels, the atmospheric water is one of the most important factors that has contributed to the degradation process. Research has proved that the $\mathrm{pH}$ value of the rainwater in the Vesuvius region is strongly influenced by the dissolution of aerosols originating from maritime, continental and anthropogenic sources [51]. The abundant atmospheric acid pollutants $\left(\mathrm{CO}_{2}, \mathrm{NO}_{x}\right.$, $\mathrm{SO}_{\mathrm{x}}$ ) can react with the mortars, causing partial dissolution of carbonate and sulphate based compounds (mainly of calcium). This dissolution process generates a water solution rich in $\mathrm{Ca}^{2+}, \mathrm{HCO}_{3}{ }^{-}$and $\mathrm{SO}_{4}{ }^{2-}$ ions with a more alkaline $\mathrm{pH}$ than the acid rain due to neutralization reactions that occurs. When this water evaporates, the gypsum reaches a saturation point and the salt precipitates on the obsidian surface or within its cracks.

In the lower part of Mirror 1, a yellow crust was also observed (see Fig. 1b). The XRF spectra in Fig. 6b indicate this incrustation has a higher Fe concentration compared to the white deposits, suggesting that the peculiar colour is probably due to crystallization of ferrous compounds. This hypothesis was confirmed by Raman analysis that identified a mixture of goethite and gypsum (see Fig. 7b). The additional presence of goethite $(\alpha-\mathrm{FeOOH}$, characteristic peaks at 299 and $388 \mathrm{~cm}^{-1}$ assigned to the $\mathrm{Fe}-\mathrm{OH}$ symmetric bending and the $\mathrm{Fe}-\mathrm{O}-\mathrm{Fe} /-\mathrm{OH}$ symmetric stretching respectively [52]) is proposed to be due to the lixiviation of iron from the filling mortars. The intense Fe signals detected by XRF and LIBS (see Fig. 9) data from the materials used in past conservation works strengthens this hypothesis.

The formation of gypsum in the crusts, mainly due to the dissolution/reprecipitation cycle, promoted layer formation on the mirror surfaces and the cracks of the obsidian, as can be observed in Fig. 5. Considering that the archaeological site of Pompeii is located in a highly polluted area [53], atmospheric sulphur $\mathrm{SO}_{\mathrm{x}}$ may also have contributed, together with the process mentioned above, in the development of those crusts.

The elemental compositions of the white crusts on Mirror 1 were investigated using the depth profiling capabilities of the LIBS system. The samples were depth profiled by collecting multiple measurements from the same spot.

Figure 10a presents data from a series of 14 LIBS pulses (shots) collected from the same area of the white crust analysed by Raman spectroscopy, see Fig. 7, in which gypsum and nitrocalcite were found. The LIBS spectra shows the presence of nitrogen, calcium, oxygen and sulphur providing evidence to support the Raman spectroscopic findings. An emission band attributed to potassium is clearly evident, suggesting potassium nitrate $\left(\mathrm{KNO}_{3}\right)$ is also in the white crust.

Figure 10b, c are a plot of the intensity of the two emission lines of nitrogen (at 867.7 and $821.6 \mathrm{~nm}$ versus pulse number). Both plots illustrate a decrease in the nitrogen intensities with increase pulse numbers reaching a constant (within the limits of an uncertainty around $\pm 5 \%$ ) value reached after shot 6 . The LIBS system has an openair path between the detector and the point of analysis. 


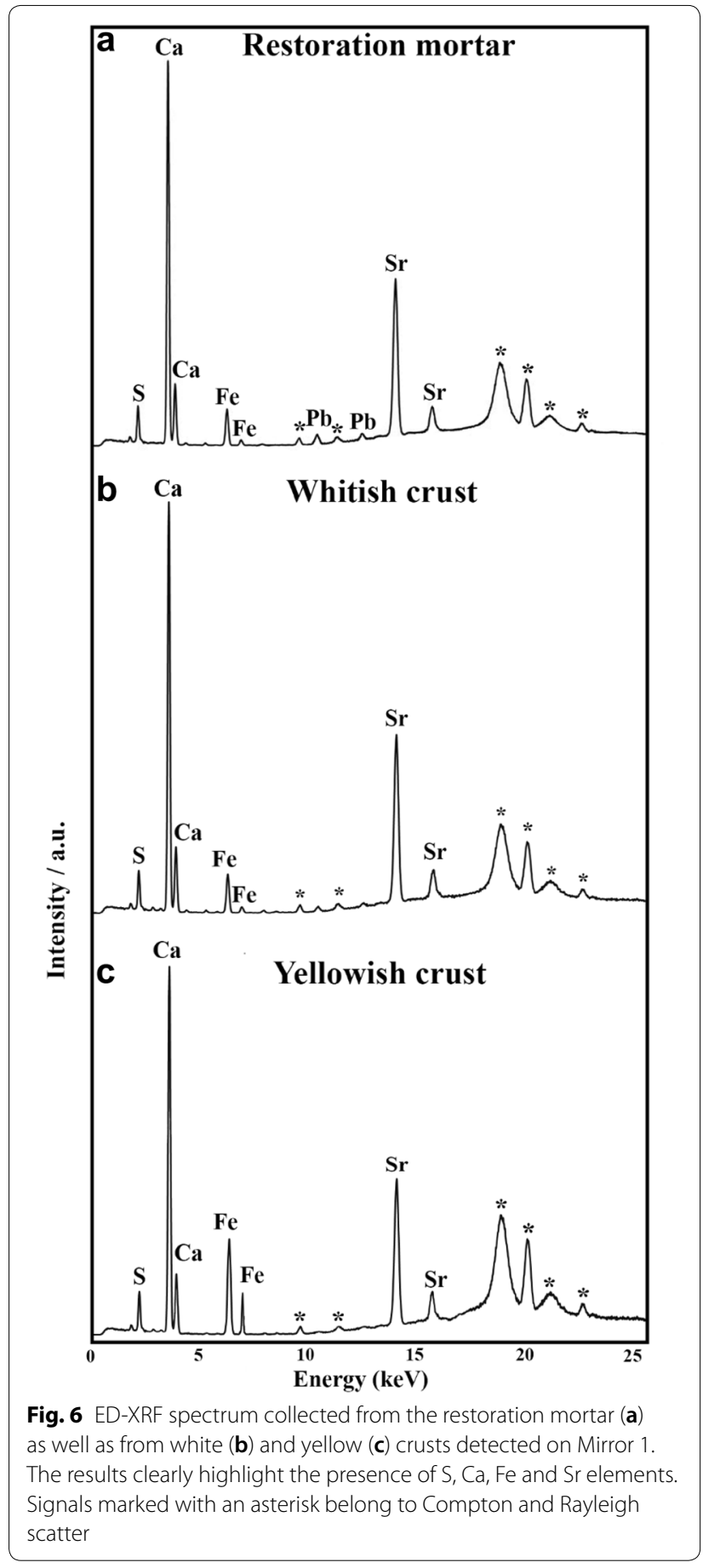

Thus, the LIBS spectrum registers the elements present in the sample and in the atmosphere, a constant nitrogen response in samples without nitrogen is the signal from the atmospheric nitrogen. This constant value (in this case from 6th to 14th shots) is present as a background in all measurements. The response of shots $1-5$ indicates that nitrogen, from nitrocalcite, is clearly present in the

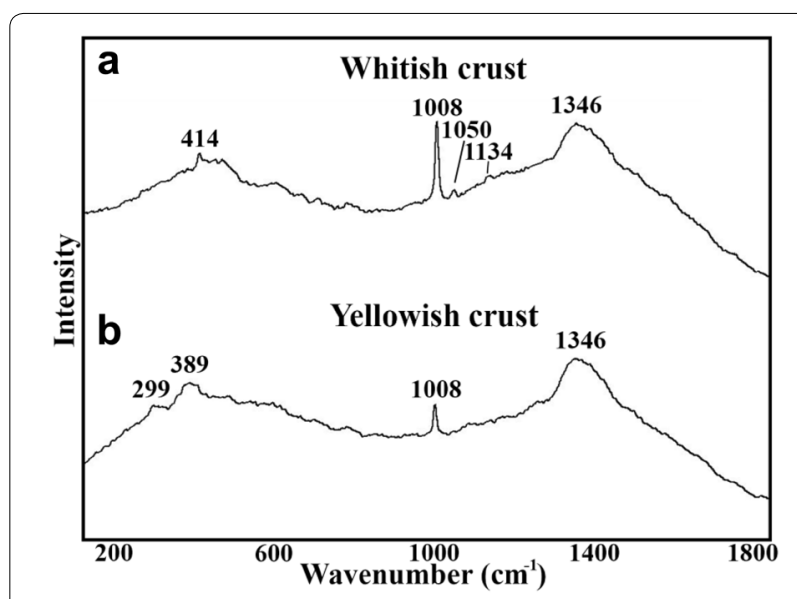

Fig. 7 Raman spectra collected from the crusts detected on Mirror 1. White crusts (a) are composed of calcium sulphate, which often display the additional presence of nitrocalcite. The yellow crust (b) is composed of a mixture of calcium sulphate and goethite

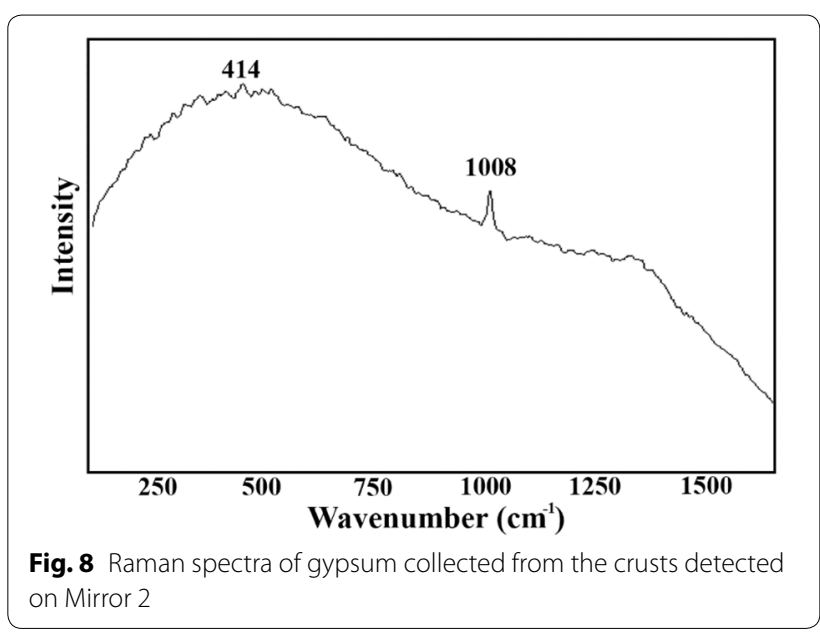

outer most layer of the analysed area in the white crust, disappearing after the 6th shot.

Figure 10a reveals the presence of a sulphur emission line. The LIBS spectrum has no sulphur signal from shots $1-3$, but in the spectra $5-7$ it is present while in spectra $8-14$ it is again absent. Assuming that gypsum is the sulphur source, we must conclude that gypsum is within the layer of nitrocalcite. The LIBS spectra after shot 8 are attributable to the elements present in obsidian, not in the white crust.

The LIBS data provide information about the stratigraphic distribution of degradation on the obsidian surface, suggesting the presence of an inner layer of gypsum covered by an outer layer of nitrocalcite. The possible explanation for the formation of the upper layer of nitrocalcite is a chemical interaction of nitric acid aerosols 

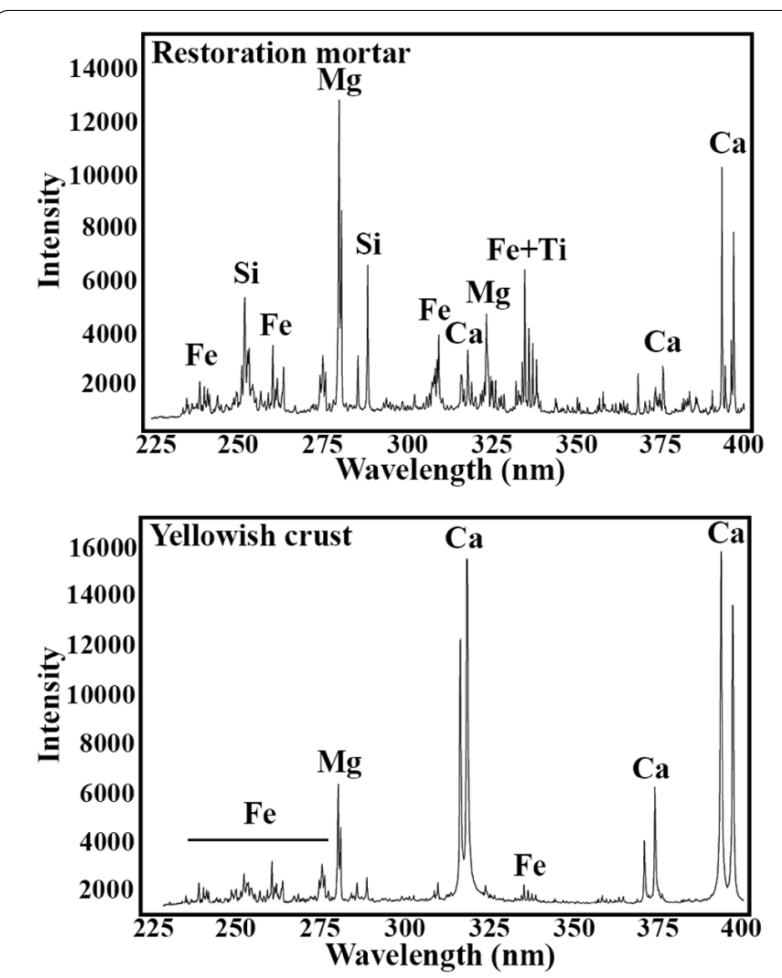

Fig. 9 Comparison between LIBS spectra collected from restoration mortar and yellow crust respectively. The major presence of Fe in the filling material applied in past conservation works is clearly observable

with gypsum. In a first step, the water of the aerosols and the dissociated nitric acid cause a partial dissolution of gypsum surface layer. Afterwards, when water evaporates, the saturation of calcium nitrate is reached, starting the precipitation of the $\mathrm{Ca}\left(\mathrm{NO}_{3}\right)_{2} \cdot 4 \mathrm{H}_{2} \mathrm{O}$ salt above the gypsum layer.

$$
\begin{gathered}
\mathrm{n} \mathrm{CaSO}_{4} \cdot 2 \mathrm{H}_{2} \mathrm{O}(\mathrm{s})+\mathrm{HNO}_{3} \rightarrow(\mathrm{n}-1) \mathrm{CaSO}_{4} \cdot 2 \mathrm{H}_{2} \mathrm{O}(\mathrm{s}) \\
+\mathrm{Ca}^{2+}+\mathrm{SO}_{4}^{2-}+\mathrm{H}^{+}+\mathrm{NO}_{3}^{-}+\mathrm{H}_{2} \mathrm{O}
\end{gathered}
$$

\section{Conclusions}

The research summarized in this work clearly underlines the advantages provided by the combined use of elemental and molecular portable analytical techniques in Cultural Heritage for characterization and preservation studies. The complementary use of Raman spectroscopy, ED-XRF and LIBS techniques provided information about the composition of the analysed artefacts, allowing the identification of obsidian as the reflective material used for both Mirrors. Analysis of the Raman spectra suggested the island of Pantelleria as a possible source of the obsidian used to manufacture the mirrors. To confirm the provenance, destructive

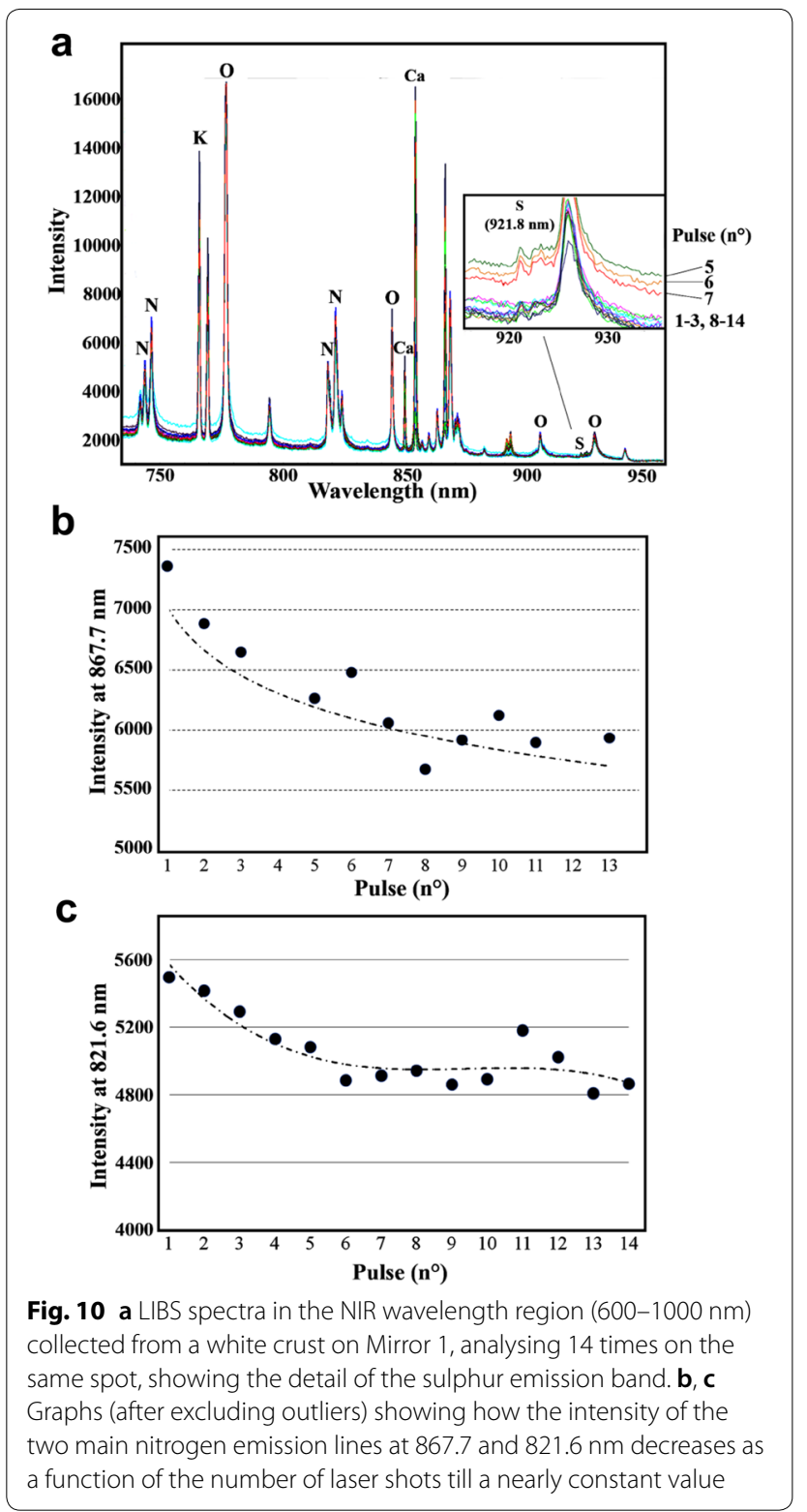

isotopic analysis must be performed [42, 43], of samples less than $200 \mathrm{mg}$ if high sensitive ICP/MS or SIMS are to be used. The Archaeological Park of Pompeii is currently considering prioritizing the preservation of the mirrors integrity, sampling from these artefacts is at the moment forbidden. However, it is hoped that the results and prospects of future studies stemming from this research will persuade the institution to undertake studies of provenance, from which numerous historical and commercial inferences could be derived, sacrificing a very small amount of material.

The multi-analytical study also identified the major degradation products and we put forward a hypothesis that led to their formation. By combining the 
elemental results with the molecular data provided by Raman spectroscopy, three different degradation processes were distinguished. It was proved that the gypsum crusts over both mirrors precipitated after a partial dissolution of the mortars used in past restoration works, which have been probably weakened by the impact of atmospheric agents. Obsidian hydration was not influenced by anthropogenic factors, but represents a natural consequence of the exposure of this vitreous material to humidity. Finally, the deposition of nitrocalcite layers (together with potassium nitrate) over the gypsum crusts is indicative of the aggressive attack of the modern atmosphere around Pompeii, where nitric acid aerosols are playing an important role in the conservation of archaeological remains.

In addition to providing important data about composition and conservation problems of unique artefacts, the results of this research will be extremely beneficial for conservators, helping them to define future conservation works. In conclusion, this manuscript represents a clear example of the advantages provided by the crossing of boundaries between Cultural Heritage and analytical research fields.

\section{Additional file}

Additional file 1: Table S1. Main Raman results and experimental condition set during the analysis of the two mirrors.

\section{Authors' contributions}

MV and SFOV performed the LIBS measurements and interpretations. NPT and MM performed the Raman analysis. HM and IM performed the XRF analysis. $\mathrm{AM}$ and $\mathrm{BN}$ supervised the measurement processes to guarantee the absence of damage to the mirrors. $\mathrm{KC}$ interpreted the chemical reactions leading to the formation of the crusts. MO and JMM designed and supervised the whole project. MV and SFOV wrote the initial draft of the manuscript. All authors read and approved the final manuscript.

\section{Author details \\ ${ }^{1}$ Department of Analytical Chemistry, University of the Basque Country (UPV/ EHU), PO Box 644, 48080 Bilbao, Spain. ${ }^{2}$ Department of Analytical Chemistry, Faculty of Pharmacy, University of the Basque Country (UPV/EHU), PO Box 450, 01080 Vitoria-Gasteiz, Spain. ${ }^{3}$ Archaeological Park of Pompeii, Pompei Scavi, Via Villa dei Misteri 2, 80045 Pompeii, Italy. ${ }^{4}$ Unesco Chair on Cultural Land- scape and Heritage, University of the Basque Country (UPV/EHU), P.O. Box 450, 01080 Vitoria-Gasteiz, Spain.}

\section{Acknowledgements}

This project has been developed under the UFI "Global Change and Heritage" project (Ref UFI11-26 UPV-EHU), funded by the University of the Basque Country (UPV/EHU), and the MADyLIN project (Ref BIA2017-87063-P), funded by the Spanish AEI (MINECO-FEDER/UE). The authors thank the Archaeological Park of Pompeii for the issuance of analysis permits. Iker Marcaida also thanks the Basque Government for his pre-doctoral grant.

\section{Competing interests}

The authors declare that they have no competing interests.

\section{Publisher's Note}

Springer Nature remains neutral with regard to jurisdictional claims in published maps and institutional affiliations.

Received: 29 November 2017 Accepted: 21 June 2018

Published online: 29 June 2018

\section{References}

1. Giacomelli L, Perrotta A, Scandone R, Scarpati C. The eruption of Vesuvius of $79 \mathrm{AD}$ and its impact on human environment in Pompei. Episodes. 2003:26:234-7.

2. Pagano M. I primi anni degli scavi di Ercolano, Pompei e Stabiae, Raccolta e studio di documenti e disegni inediti. 1st ed. Roma: L'erma di Bretschneider; 2005

3. Chaney E. The evolution of the grand tour: Anglo-Italian cultural relations since the Renaissance. 1st ed. London: Frank Class Publishers; 1998.

4. D'Aprile M. Planned conservation and cultural enhancement strategy: the Vesuvius's UNESCO archeological site management. In: Della Torre S, editor. Sguardi ed esperienze sulla conservazione del patrimonio storico architettonico. Firenze: Nardini; 2014. p. 189-98.

5. Data visitors 2016. http://www.statistica.beniculturali.it/rilevazioni/musei/ Anno\%202016/MUSEI_TAVOLA8_2016.pdf. Accessed 28 Oct 2017.

6. Maguregui M, Castro K, Morillas H, Trebolazabala J, Knuutinen U, Wiesinger R, Schreiner M, Madariaga JM. Multi-analytical approach to explain the darkening process of hematite pigment in paintings from ancient Pompeii after accelerated weathering experiments. Anal Methods. 2014;6:372-8

7. Merello P, Beltrán P, García-Diego FJ. Quantitative non-invasive method for damage evaluation in frescoes: Ariadne's House (Pompeii, Italy). Environ Earth Sci. 2016;75:165-74

8. Grifa C, Barba S, Fiorillo F, Germinario C, Izzo F, Mercurio M, Musmeci D, Potrandolfo A, Santoriello A, Toro P, Langella A. The domus of Octavius Qartio in Pompeii: damaged diagnosis of the masonries and frescoed surfaces. Int J Conserv Sci. 2016;2:885-900.

9. Neiman MK, Balonis M, Kakoulli I. Cinnabar alteration in archaeological wall paintings: an experimental and theoretical approach. Appl Phys A. 2015;121:915-38.

10. International Council on Monuments and Sites (ICOMOS). International charter for the conservation and restoration of monuments and sites. 1965. https://www.icomos.org/charters/venice_e.pdf. Accessed 28 Oct 2017.

11. IBeA research group. https://www.ehu.eus/es/web/ibea/home. Accessed 28 Oct 2017.

12. APUV project. http://apuv-ibea.com/es/. Accessed 28 Oct 2017

13. Maguregui M, Knuutinen U, Castro K, Madariaga JM. Raman spectroscopy as a tool to diagnose the impact and conservation state of Pompeian Second and Fourth style wall paintings exposed to diverse environments (House of Marcus Lucretius). J Raman Spectrosc. 2010;41:1400-9.

14. Maguregui M, Knuutinen U, Martinez-Arkarazo I, Castro K, Madariaga JM. Thermodynamic and spectroscopic speciation to explain the blackening process of hematite formed by atmospheric $\mathrm{SO}_{2}$ impact: the case of Marcus Lucretius House (Pompeii). Anal Chem. 2011;83:3319-26.

15. Maguregui M, Knuutinen U, Martínez-Arkarazo I, Giakoumaki A, Castro K, Madariaga JM. Field Raman analysis to diagnose the conservation state of excavated walls and wall paintings in the archaeological site of Pompeii (Italy). J Raman Spectrosc. 2012;11:1747-53.

16. Madariaga JM, Maguregui M, de Vallejuelo SFO, Knuutinen U, Castro K, Martinez-Arkarazo I, Giakoumaki A, Pitarch A. In situ analysis with portable Raman and ED-XRF spectrometers for the diagnosis of the formation of efflorescence on wall paintings of the Insula IX 3 (Pompeii, Italy). J Raman Spectrosc. 2014:45:1059-67.

17. Veneranda M, Prieto-Taboada N, de Vallejuelo SFO, Maguregui M, Morillas H, Marcaida I, Castro K, Madariaga JM, Osanna M. Biodeterioration of Pompeian mural paintings: fungal colonization favoured by the presence of volcanic material residues. Environ Sci Pollut Res. 2017:24:19599-608. 
18. Veneranda M, Prieto-Taboada N, de Vallejuelo SFO, Maguregui M, Morillas H, Marcaida I, Castro K, Madariaga JM, Osanna M. In-situ multianalytical approach to analyze and compare the degradation pathways jeopardizing two murals exposed to different environments (Ariadne House, Pompeii, Italy). Spectrochim Acta A Mol Biomol Spectrosc. 2018;203:201-9.

19. Marcaida I, Maguregui M, de Vallejuelo SFO, Morillas H, Prieto-Taboada N, Veneranda M, Castro K, Madariaga JM. In situ X-ray fluorescence-based methodology to differentiate among red ochre and thermally transformed yellow ochre to red pigments of the wall paintings from Pompeii. Anal Bioanal Chem. 2017;409:3853-60.

20. Archaeological Park of Pompeii. http://www.pompeiisites.org/. Accessed 28 Oct 2017.

21. Hackworth Petersen L. Collecting gods in roman houses: the House of the Gilded Cupids (VI.16.7, 38) at Pompeii. Arethusa. 2012;45:319-32.

22. Powers J. Beyond Painting in Pompeii's houses: wall ornaments and thir patrons. In: Poehler E, Flohor M, Cole K, editors. Pompeii: art, industry, and infrastructure. Oxford: Oxbow Books; 2011. p. 10-32.

23. Veneranda M, Irazola M, Díez M, Iturregui A, Aramendia J, Castro K, Madariaga JM. Raman spectroscopic study of the degradation of a middle age mural painting: the role of agricultural activities. J Raman Spectrosc 2014;45:1110-8

24. Castro K, Pérez-Alonso M, Rodríguez-Laso MD, Fernández LA, Madariaga JM. On-line FT-Raman and dispersive Raman spectra database of artists' materials (e-VISART database). Anal Bioanal Chem. 2015;382:248-58.

25. Lafuente B, Downs RT, Yang H, Stone N. The power of databases: the RRUFF project. In: Armbruster T, Danisi RM, editors. Highlights in mineralogical crystallography. Berlin:W. De Gruyter; 2015. p. 1-30.

26. NIST database of atomic spectral data. https://www.nist.gov/pml/atomi c-spectra-database. Accessed 28 Oct 2017

27. Melchior-Bonnet S. The mirror: a history. 1st ed. Hove: Psychology press LTD; 2001.

28. Gomez-Nubla L, Aramendia J, de Vallejuelo SFO, Alonso-Olazabal A, Castro K, Zuluaga MC, Ortega LA, Murelaga X, Madariaga JM. Multispectroscopic methodology to study Libyan Desert glass and its formation conditions. Anal Bioanal Chem. 2017:409:3597-610.

29. Tuschel D. Selecting an excitation wavelength for Raman spectroscopy. Spectroscopy. 2016;31:14-23.

30. White WB, Minser DG. Raman spectra and structure of natural glasses. Non-Cryst Solids. 1984;67:45-59.

31. Bellot-Gurlet L, Le Bourdonnec FX, Poupoeau G, Debernet S. Raman micro-spectroscopy of western Mediteranean obsidian glass: one step towards provenance studies? J Raman Spectrosc. 2004:35:671-7.

32. Williams-Thorpe O. Review article-Obsidian in the Mediterranean and the near east: a provenancing success story. Archaeometry. 1995;32:217-48

33. Remus JJ, Gottfried JL, Harmon RS, Draucker A, Baron D, Yohe R. Archaeological applications of laser-induced breackdown spectroscopy: an example from the Coso Volcanic Field, California, using advanced statistical signal processing analysis. Appl Opt. 2010;49:120-31.

34. Rogers AK, Stevenson CM. Protocols for laboratory hydration of obsidian, and their effect on hydration rate accuracy: a Monte Carlo simulation study. J Archaeol Sci Rep. 2017;16:117-26.

35. Heide G, Müller B, Kloess G, Moseler D, Frischat GH. Structural classification of natural non-crystalline silicates. J Non-Cryst Solids. 2013:323:68-71

36. Friedman I, Smith RI, Long WD. Hydration of natural glass and formation of perlite. Geol Soc Am Bull. 1966;77:323-8.

37. Hull K. Reasserting the utility of obsidian hydration dating: a temperature-dependent empirical approach to practical temporal resolution with archaeological obsidians. J Archaeol Sci. 2001;28:1025-40.
38. Liritzis I, Laskaris N. Fifty years of obsidian hydration dating in archaeology. J Non-Cryst Solids. 2013;357:2011-23.

39. Nakazawa Y. The significance of obsidian hydration dating in assessing the integrity of Holocene midden, Hokkaido, northern Japan. Quat Int. 2016:397:474-83.

40. Reepmeyer C, O'Connor S, Brockwell S. Long-term obsidian use at the Jerimalai rock shelter in East Timor. Archaeol Ocean. 2011;46:85-90.

41. Cioni R, Beragnini A, Santacroce R, Andronico D. Explosive activity and eruption scenarios at Somma-Vesuvius (Italy): towards a new classification scheme. J Volcanol Geotherm Res. 2008;178:331-46.

42. Beherec MA, Levy TE, Tirosh O, Najjar M, Knabb KA, Erel Y. Iron age nomads and their relation to copper smelting in Faynan (Jordan): trace metal and $\mathrm{Pb}$ and $\mathrm{Sr}$ isotopic measurements from the Wadi Fidan 40 cemetery. J Archaeol Sci. 2016;65:70-83.

43. Bode M, Hauptmann A, Mezger K. Tracing Roman lead sources using lead isotope analyses in conjunction with archaeological and epigraphic evidence - a case study from Augustan/Tiberian Germania. Archaeol Anthropol Sci. 2009;1:177-94.

44. Antonelli F, Lazzarini L. Mediterranean trade of the most widespread Roman volcanic millstones from Italy and petrochemical markers of their raw materials. J Archaeol Sci. 2010;37:2081-92.

45. Cann JR, Renfrew R. The characterization of obsidian and its application to the Mediterranean region. Proc Prehist Soc. 1966;8:111-33.

46. Carter EA, Hargreaves MD, Kononenko N, Graham I, Edwards HGM, Swarbrick B, Torrence R. Raman spectroscopy applied to understanding Prehistoric Obsidian Trade in the Pacific Region. Vib Spectrosc. 2009;50:116-24.

47. Carter EA, Kelloway SJ, Kononenko N, Torrence R. Raman spectroscopic studies of obsidian. In: Edwards H, Vandenabeele P, editors. Analytical archaeometry: selected topics. Cambridge: RSC Publishing; 2012. p. 323-50.

48. Brooker $\mathrm{MH}$, Irish DE. Infrared and Raman spectral studies of $\mathrm{KNO}_{2}-\mathrm{KNO}_{3}$ solutions. Can J Chem. 1968;46:229-33.

49. Prieto-Taboada N, de Vallejuelo SFO, Veneranda M, Marcaida I, Morillas H, Maguregui M, Castro K, De Carolis E, Osanna M, Madariaga JM. Study of the soluble salts formation in a recently restored house of Pompeii by in situ Raman spectroscopy. Sci Rep. 2018;8:1613.

50. Morillas H, Maguregui M, Gómez-Laserna O, Trebolazabala J, Madariaga JM. Characterisation and diagnosis of the conservation state of cementitious materials exposed to the open air in XIX century lighthouses located on the coast of the Basque Country: 'The case of Igueldo lighthouse, San Sebastian, North of Spain. J Raman Spectrosc. 2012;44:1630-6.

51. Madonia P, Liotta M. Chemical composition of precipitation at Mt. Vesuvius and Vulcano Island, Italy: volcanological and environmental implications. Environ Earth Sci. 2010;61:159-71.

52. Legodi MA, de Waal D. The preparation of magnetite, goethite, hematite and maghemite of pigment quality from mill scale iron waste. Dyes Pigments. 2007;74:161-8.

53. Methods for the integrated assessment of the environmental and health impact of atmospheric pollution. https://www.vilas.it/. Accessed 10 May 2018

\section{Submit your manuscript to a SpringerOpen ${ }^{\odot}$ journal and benefit from:}

- Convenient online submission

- Rigorous peer review

- Open access: articles freely available online

- High visibility within the field

- Retaining the copyright to your article

Submit your next manuscript at $\boldsymbol{\nabla}$ springeropen.com 